\title{
Chinese deserts and sand fields in Last Glacial Maximum and Holocene Optimum
}

\author{
LU HuaYu ${ }^{1 *}$, YI ShuangWen ${ }^{1}, \mathrm{XU}$ ZhiWei ${ }^{1}$, ZHOU YaLi ${ }^{2}$, ZENG Lin ${ }^{1}$, ZHU FangYing ${ }^{1}$, \\ FENG Han ${ }^{1}$, DONG LiNa ${ }^{1}$, ZHUO HaiXin ${ }^{1}$, YU KaiFeng ${ }^{1}$, MASON Joseph ${ }^{3}$, \\ WANG XiaoYong ${ }^{1}$, CHEN Ying Yong ${ }^{1}$, LU Qi ${ }^{4}$, WU Bo ${ }^{4}$, DONG ZhiBao, \\ QU JianJun ${ }^{5}$, WANG XunMing ${ }^{5} \&$ GUO ZhengTang ${ }^{6}$
}

${ }^{1}$ School of Geographic and Oceanographic Sciences, Institute for Climate and Global Change Research, Nanjing University, Nanjing 210093, China

${ }^{2}$ College of Tourism and Environment, Shaanxi Normal University, Xi'an 710062, China;

${ }^{3}$ Department of Geography, University of Wisconsin Madison, WI 53706, USA;

${ }^{4}$ Institute of Desertification Studies, Chinese Academy of Forestry, Beijing 100091, China;

${ }^{5}$ Cold and Arid Regions Environmental and Engineering Research Institute, Chinese Academy of Sciences, Lanzhou 730000, China;

${ }^{6}$ Institute of Geology and Geophysics, Chinese Academy of Sciences, Beijing 100029, China

The Last Glacial Maximum (LGM, c. 26-16 ka) and the Holocene Optimum (HO, c. 9-5 ka) were characterized by cold-dry and warm-wet climates respectively in the recently geological Earth. How Chinese deserts and sand fields responded to these distinctive climatic changes is still not clear, however. To reconstruct environments of the deserts and sand fields during the LGM and $\mathrm{HO}$ is helpful to understand the forcing mechanisms of environment change in this arid region, and to test paleoclimatic modeling results. Through our long-term field and laboratory investigations, 400 optically stimulated luminescence (OSL) ages and more than 100 depositional records in the Chinese deserts and sand fields were obtained; on the basis of these data, we reconstruct spatial distributions of the deserts and sand fields during the LGM and HO. Our results show that the sand fields of Mu Us, Hunshandake, Horqin and Hulun Buir in northern and northeastern China had expanded 25\%, 37\%, 38\% and 270\%, respectively, during the LGM; the sand fields of Gonghe in the northeastern Qinghai-Tibetan Plateau had expanded 20\%, and the deserts of Badain Jaran, Tengger in central northern China had expanded $39 \%$ and $29 \%$ separately during the LGM; the deserts of Taklimakan, Gurbantünggüt and Kumtag in northwestern China had expanded 10\%-20\% respectively, compared to their modern areas. On the other hand, all of the sand fields were nearly completely covered by vegetation during the HO; the deserts in northwestern and central northern China were reduced by around 5\%-20\% in area during this time. Lakes in this arid region were probably expanded during the $\mathrm{HO}$ but this conclusion needs more investigation. Compared with the geological distributions of deserts and sand fields, human activity has clearly changed (expanded) the area of active sand dunes at the present time. Our observations show that environmental conditions of Chinese deserts and sand fields are controlled by regional climate together with human activity.

deserts and sand fields in China, Last Glacial Maximum, Holocene Optimum, OSL dating, active sand dunes

Citation: $\quad$ Lu H Y, Yi S W, Xu Z W, et al. Chinese deserts and sand fields in Last Glacial Maximum and Holocene Optimum. Chin Sci Bull, 2013, 58: 2775-2783, doi: $10.1007 / \mathrm{s} 11434-013-5919-7$

There is an area of around $2.0 \times 10^{6} \mathrm{~km}^{2}$ made up by deserts, sand fields and potentially desertified land in China [1];

*Corresponding author (email: huayulu@nju.edu.cn) their environment and ecosystem are vulnerable to climatic change and human activity. In addition, changes in the deserts and sand fields have also influenced climate and human life at local to hemispheric scales, thus, to understand 
environment changes in these deserts and sand fields is not only a scientific question, it is also important to combating desertification. The deserts and sand fields have changed greatly in time and space during late Quaternary, and to reconstruct spatial changes in extent of active dunes is particular important [2-6]. There were a few reconstructions of desert changes during the Last Glacial Maximum (LGM) and Holocene Optimum (HO) [7-26], however, because of limited dating work and field investigation, the results need tested. Moreover, some previous reconstructions were speculation based on comparison with paleoclimatic records, without direct and specific stratigraphic evidence; therefore, the conclusions [7-26] should be clarified. In China, some early investigations have advanced our knowledge of environment changes in the desert and sand fields, but there were quite a few issues that were not well resolved in this previous research, including: (1) Because of the limitation of dating techniques, accurate, independent high-quality ages for the deserts and sand fields were limited in number; previous research always compared the sand deposition with established time series such as that of Chinese loesspaleosol sequence and marine oxygen isotope stages to obtain age control $[9,10,15-17,21-26]$ which was quite speculative. (2) The ages were not well-distributed spatially across the deserts and sand fields. (3) By reconstructing changes in the boundaries of deserts and sand fields only indirectly from paleoclimatic zone migration, without direct evidence, has probably led to misleading conclusions. (4) There was not a clear distinction made between the deserts and sand fields dominated by Asian monsoon circulation, the North Hemisphere westerlies and even local landform effects on climate, therefore, it was difficult to identify forcing mechanisms of change in specific deserts and sand fields. These previous limitations hindered proper understanding of the spatial changes of Chinese deserts and sand fields during the late Quaternary.

Chinese deserts and sand fields are mainly located in northern China, with dry climate (we do not discuss the scattered and fragmentary sand fields in southeast China and on the Qinghai-Tibetan Plateau), controlled separately by Asian monsoon circulation and/or the Northern Hemisphere westerlies. The sand fields of Mu Us, Hunshandake, Horqin and Hulun Buir in central northern China are dominated by the monsoon climate, whereas the deserts of Taklimakan, Gurbantünggüt and Kumtag are not influenced by the monsoon climate (some suggest that these deserts are dominated by the westerlies [27-31]). The deserts between northwestern and northeastern China such as Badain Jaran, Tengger, Ulan Buh and Hobq are located in the marginal region of the Asian monsoon climate, and are also very dry. Therefore, the different atmosphere circulations that control the deserts and sand fields' environments should be separately investigated.

Since the spring of 1997 , we have investigated these deserts and sand fields in order to reconstruct their environ- ment changes during the late Quaternary; in particular in the past six years, we investigated the sediments and depositional records by gridding-route reconnaissance in the field and collected numerous samples which were dated by the optically stimulated luminescence (OSL) technique and measured to obtaining proxy indexes of the environment changes. On the basis of this long-term study, we try to reconstruct Chinese deserts and sand fields in the LGM and HO, and, compare the reconstruction results with the modern deserts and sand fields, to investigate possible forcing mechanisms of environmental change in the deserts and sand fields.

\section{Methods and data}

Figure 1 shows distribution of the modern deserts, Gobi and sand fields in northern China [32]. We produced this map based on combination of remote sensing (RS) including Enhanced Thematic Mapper (ETM) images and the spectral angle method, observations located with global positioning systems (GPS), and geographic information system (GIS) analysis. We first applied geometric precision correction, image mosaicking, wave band combination and image enhancement to ETM images from 2010; then bands 7, 5 and 2 of these enhanced ETM images were used to establish markers of desertification. Third, the spectral angle method was used to identify margins of active dunes, soil and vegetation covers. Observations in the field, located by GPS were used to correct the boundary data. An existing data set was combined with our results to create a new GIS database for the deserts and sand fields, containing numerical data of landforms, soils and vegetation.

Figure 2 shows the detailed field reconnaissance in Chinese deserts and sand fields as an example; we have chosen good outcrops for sampling through extensive field reconnaissance. At each site, the location, stratigraphic and sedimentary characteristics were carefully logged. Samples were dated by OSL technique and measured for grain size, magnetic susceptibility and organic matter content in order to identify depositional environment. Previous studies [8-10,18,21] have shown that the aeolian deposits in marginal regions of these deserts and sand fields can be used as indicators of desert and sand field expansion and contraction during the late Quaternary. That is, when the East Asian winter monsoon circulation was strengthened, the climate in these regions was dry and the wind velocity was increased, the sand dune would be active and the deserts and sand fields expanded along direction of the strengthened monsoon wind; on the other hand, the strengthened East Asian summer monsoon circulation brought more precipitation to this dry region, vegetation cover expanded and stabilized the active sand dunes, so the desert and sand field were probably covered by loess and sandy soil. The sand, loess and soil in the depositional sequences can be used as proxy indicators of the deserts and sand fields change in the 


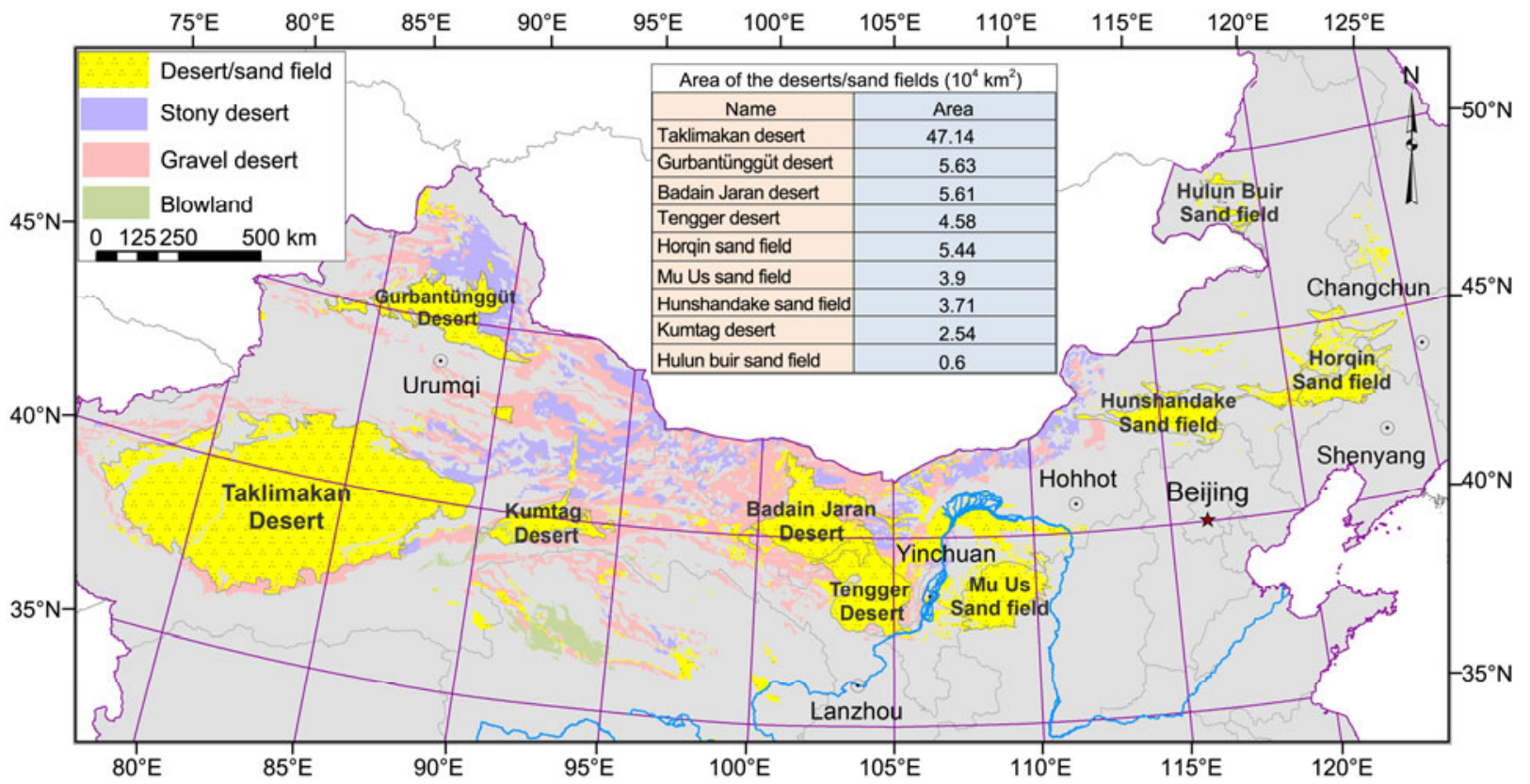

Figure 1 Chinese deserts and sand fields obtained by newly remote sense images interpretation and the existed geographic information data.

past. After dating many sedimentary sites near the margins of the deserts and sand fields, we used both of the ages and depositional records to reconstruct the distribution of active sand dunes and soils [8-10,18,21]; many dated sites are used in combination to delineate borders of the deserts and sand fields in the LGM and HO.

Figure 3 shows specific depositional records with the OSL ages and proxy indicators of the paleoenvironment, for an example. The single aliquot technique using coarse quartz particles is used [33] to date the samples; the chemically extracted pure $90-150 \mu \mathrm{m}$ particles were measured by Risøe TL/OSL-DA-20C/D OSL reader to obtain equivalent dose rate; for estimating dose rate to grains, concentrations of ${ }^{238} \mathrm{U},{ }^{232} \mathrm{Th}$ and ${ }^{40} \mathrm{~K}$ were measured by Neutron Activation Analysis (NAA). Thus, more than 400 OSL ages have been obtained [18,34-44]; at the same time, the grain size distribution, magnetic susceptibility and organic matter content were measured. As a total, more than 100 depositional sections were analyzed, plus the previous published ages $[8,10,11,21,45-57]$ that can be used to identify sediments deposited in the LGM and HO, to provide estimation of the borders of the deserts and sand fields during that time (Figure 4 and Table 1) [32].

\section{Results}

Compared with the modern distribution, the deserts of Taklimakan, Gurbantünggüt and Kumtag were expanded 10\%$20 \%$ during the LGM; the deserts of Badain Jaran and Tengger were expanded $39 \%$ and $29 \%$ respectively, and the sand fields of $\mathrm{Mu}$ Us, Hunshandake, Horqin and Hunlun Buir were expanded $25 \%, 37 \%, 38 \%$ and $270 \%$ respectively during the LGM; The Gonghe Basin dune field was expanded 20\% (Figure 4, Table 1, all compared with the modern areas). There was a great change in the sand fields and deserts during the HO: the sand field of Hulun Buir, Horqin, Hunshandake and Mu Us were nearly completely covered by vegetation and black sandy loam soil or black sandy chestnut soil, as was the Gonghe Basin sand field; the margins of the Tengger, Badan Jarain, Kumtag and Takilamakan deserts were shifted near the piedmonts of the Qilian Mountains, Kunlun Mountains, Altyn Tagh Mountains and Tianshan mountains, where conditions were relatively humid during the HO and loess or loess-like sediment was deposited with thicknesses of several meters to tens of meters, indicating retreat of the active sand dunes over an estimated distance of $20-60 \mathrm{~km}$. In contrast to the great retreat (several hundred kilometers) of the sand fields in northeastern China, the margins of the deserts in northwestern and central northern China had a smaller change; they were mainly characterized by active sand dunes even during the HO, which was also the case in the Qaidam Basin [57]. This finding supports the view that climatically driven evolution of sand dune activity differed between northwestern and northeastern China.

\section{Discussions}

\subsection{Reliability and accuracy of the reconstruction of deserts and sand fields}

Our results are based on long-term field reconnaissance and numerous independent OSL ages. In particular, we used a gridding-routes strategy to investigate depositional records in these deserts and sand fields, paying particular attention 

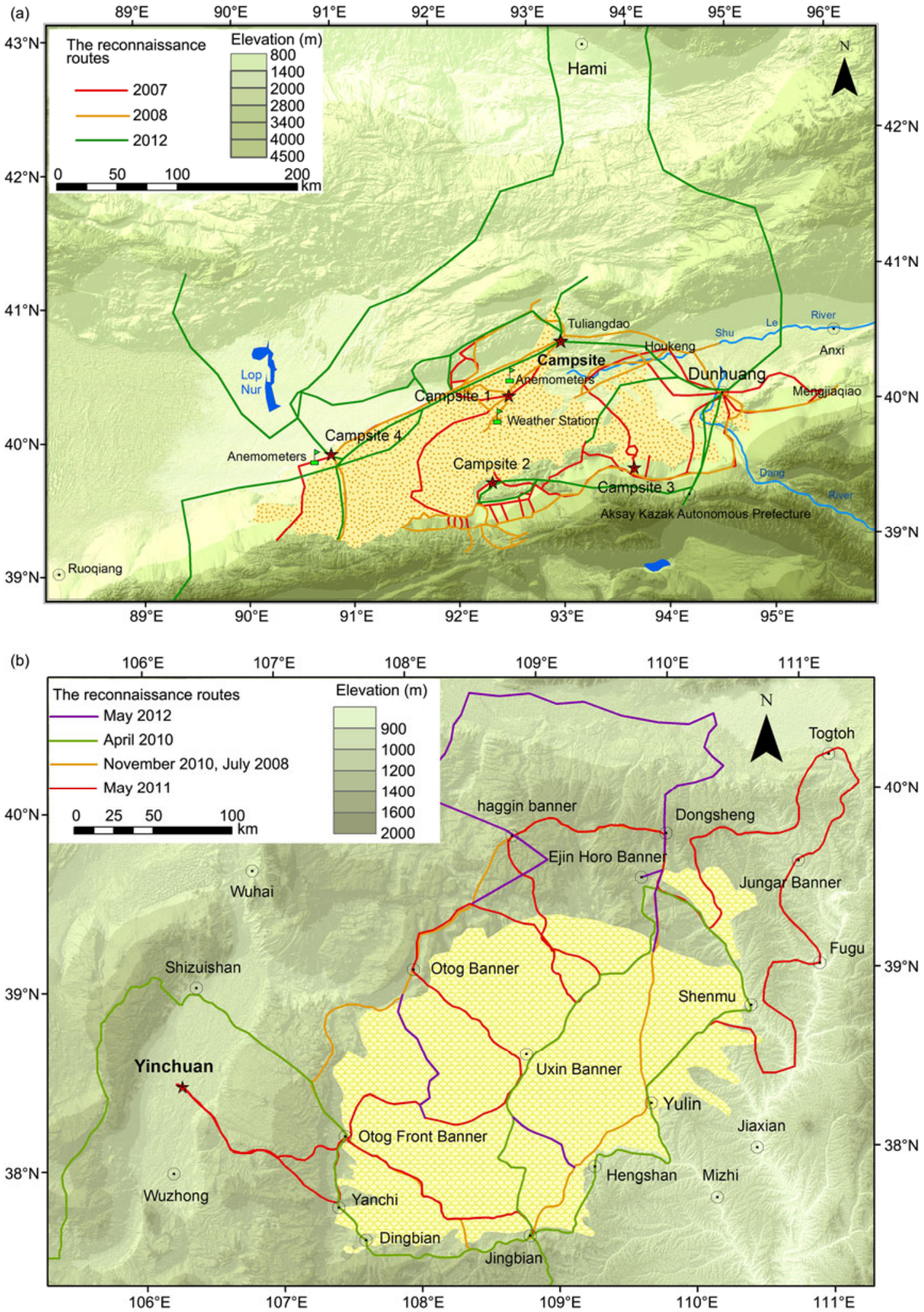

Figure 2 The reconnaissance routes in the deserts and sand fields, as an example. (a) Kumtag desert; (b) Mu Us sand field.

to depositional exposures along transects across boundaries between the sand fields and adjacent loess. Thus, the uncertainty of reconstructed border locations is less then $10 \mathrm{~km}$ in some places, providing the most accurate results to date in delineating the distribution of Chinese deserts and sand fields during the LGM and HO. In addition, significant improvement of the OSL dating technique has provided rapid [58], accurate and replicable dating for these aeolian sand sediments 


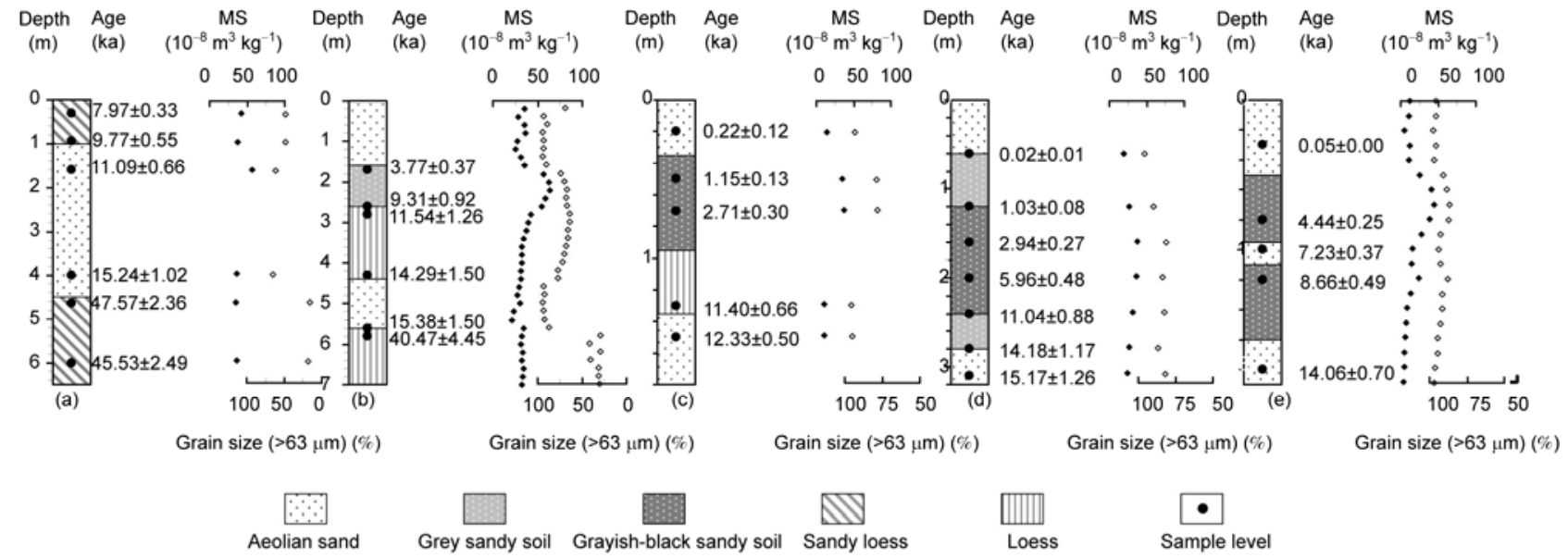

Figure 3 Representative sections investigated by this study. (a) South margin of Tengger Desert; (b) Mu Us sand field; (c) Hunshandake sand field; (d) south margin of Horqin sand field; (e) Hulun Buir sand field.

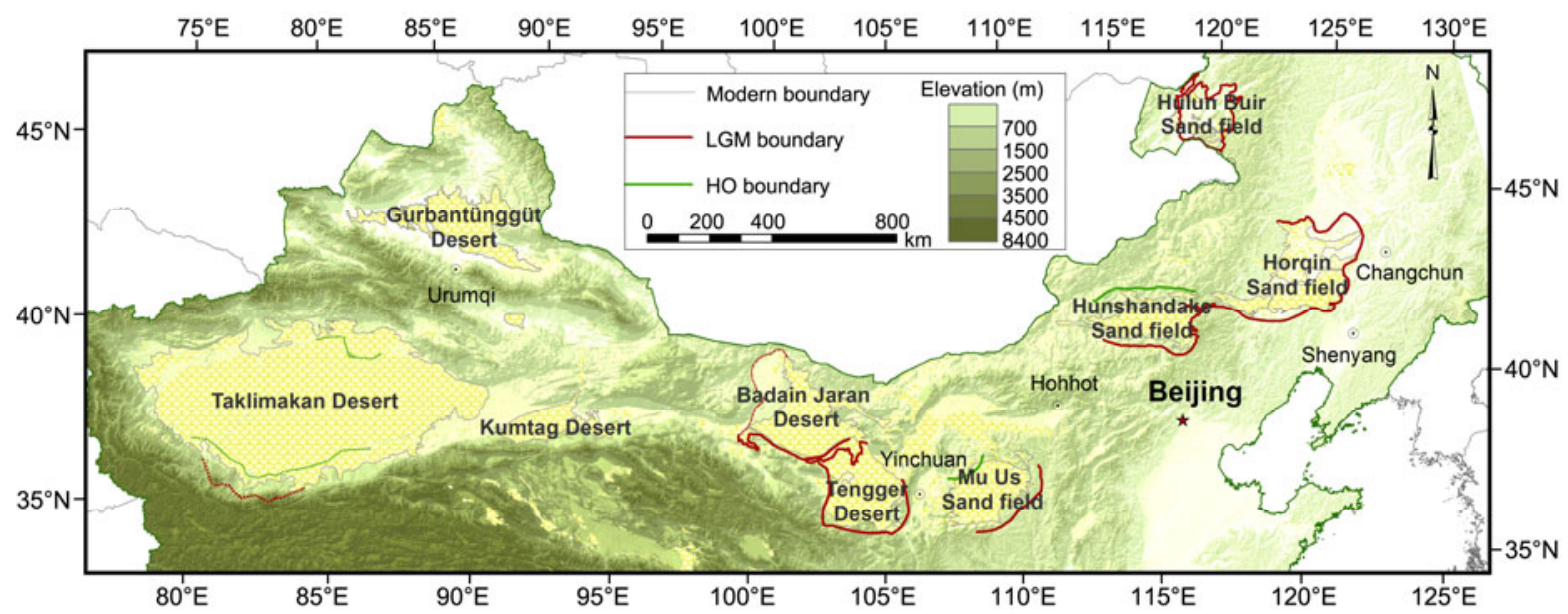

Figure 4 Chinese deserts and sand fields during the LGM and HO.

Table 1 Quantitative estimation of distribution of the active dunes in Chinese deserts and sand fields during the LGM and HO

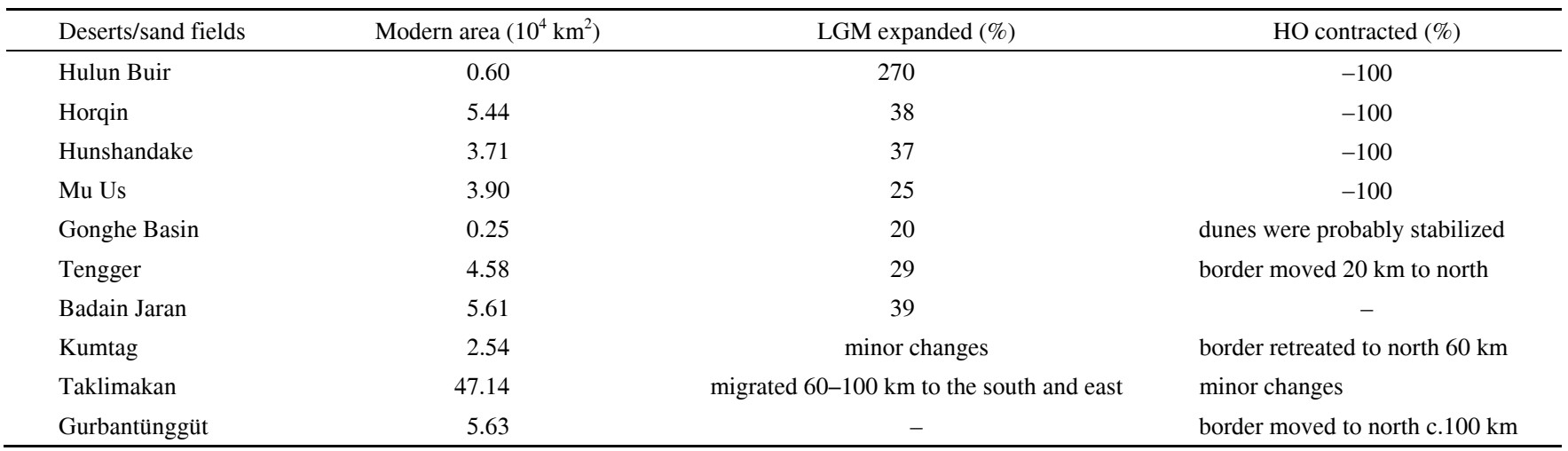

age with errors less than $10 \%$, therefore, we believe that this study presents the most accurate and reliable results for reconstructing the spatial distribution of Chinese deserts and sand fields during the late Quaternary. Moreover, this study provides the first evidence that the deserts in northwestern
China and the sand fields in northeastern China have evolved differently during the LGM and HO, showing that the area of active dunes in the northeastern China has had a greater amplitude of fluctuation than that in central northern and northwestern China. This finding demonstrates that 
climate was an important factor that dominated the dune field evolution.

The deserts and sand fields in China are mainly scattered in the Cenozoic basins (Figure 1). Our reconnaissance along transects across desert and sand field boundaries allowed us to identify buried soils or sands that are direct evidence of border migration. This kind of work has never been undertaken before, unfortunately. Previous research suggested that subtropical deserts could have expanded to $30^{\circ} \mathrm{N}$ and $30^{\circ} \mathrm{S}$ during the LGM, so that half of the land area of the continents was covered by deserts [7] (the modern proportion is 22.6\%, UNEP, 2006, Global Deserts Outlook. http:// www.unep.org/geo/gdoutlook/). However, these previous results are quite speculative because the authors deduced the desert borders indirectly based on paleoclimatic reconstructions, unsupported by direct stratigraphic evidence. In China, previous investigators used precipitation of $200-400 \mathrm{~mm}$ as the boundary between the loess and sand field, thus, they concluded that border of sand fields and deserts would move south to $30^{\circ} \mathrm{N}$ during the LGM, in accordance with the climatic zone migration. If so, the desert border would be located at the line along Hangzhou-Nanchang-ChangeshaChengtu to the Gongga Mountains [59], within the present monsoon core region with an annual precipitation more than $1000 \mathrm{~mm}$. Indeed, the reference [59] used the word "desert" as a climatic zone indicator but not a real desert, and an actual desert landscape never existed in this monsoonal evergreen region at the LGM or since that time. Unfortunately, this concept was misunderstood, so that someone believed the region from Hangzhou, to Nanchang, Changsha, Chengdu and Gongga Mountains was covered by desert in the LGM. In fact, it is difficult to find aeolian sand deposits more than 50-60 km beyond the modern active dune area. For instance, the aeolian sand and silt form continuous deposits southward from the modern $\mathrm{Mu}$ Us sand field. We scrutinized extensive outcrops to identify any buried sand along transects from the $\mathrm{Mu}$ Us dune field to the Loess Plateau, and we found the sand deposits of the LGM were replaced by loess 50-60 km away from the modern sand dunes; we did not find sand deposits of the LGM even in the Yan'an region, less than $100 \mathrm{~km}$ away from the $\mathrm{Mu}$ Us dune field. This observation clearly reveals that the Mu Us sand dunes did not migrate to more than $100 \mathrm{~km}$ away during the LGM, compared with the modern border. Thus, LGM expansion of the dune field was quite limited.

For a long-time, the monsoon precipitation has been regarded as the most important factor that controls the border location of Chinese deserts and sand fields [8,13,17-19,21, $23,33,59,60]$. This is accurate for the sand fields in the east of Helan Mountains, however, the deserts west of the Helan Mountains, especially the Kumtag desert and Taklimakan desert are barely influenced by the monsoon circulation, and their evolution and environment change were different from the dune fields in the northeastern China. An early paper [61] concluded that the Chinese deserts and sand fields probably changed in different style between the west and the east sides of Helan Mountains, our findings support this conclusion; the border migration amplitude of the nonmonsoon region was much smaller than that of the monsoon dominated region.

\subsection{Factors that force Chinese deserts and sand fields' changes in LGM and HO}

The distribution of deserts and sand fields in China is dominated by climate (aridity and wind velocity), sand source production, topography and human activity. We believe that the major changes of the sand fields in the northeastern China during the LGM and HO are mainly controlled by paleoclimatic changes. That is, the LGM was characterized by a cold and dry climate, with weaker water vapor transport and atmospheric circulation than today, lower sea-level and increased continentality, and precipitation decreased in inland China at that time. There is evidence for both strengthened wind and increased aridity during the LGM [19,62,63], and these two factors directly forced the expansion of the active dunes. On the other hand, the rise of sea-level, increased water vapor transport and atmospheric circulation and reduced wind velocity in the HO drove decrease of the sand dune mobility, with expansion of vegetation and soil covers. However, climate is not the unique factor that controls the deserts and sand fields' variations. In the deserts of Taklimakan, Kumtag and Qaidam, active sand dunes are located in basins bounded by high mountains, therefore, even though there was a significant climate changes between the LGM and HO, the active sand dunes never expanded across the high mountains such as the Altyn Tagh, the high topography clearly blocked expansion of the active sand dunes to the south.

The modern climate in the sand fields in northeastern China is more close to the climate of the HO (interglaciation) than that of the LGM (glaciation), therefore, the modern border location of the sand fields and deserts should be closer to that of the HO rather than the LGM, if the climate was the most important and unique factor that controlled the active dune distribution. However, our reconstructions show that area of the modern sand fields is $20 \%-40 \%$ less than that of the LGM, but is at least several times more than that of the HO (Figure 4 and Table 1). This observation shows that the distribution of the modern active dunes is more likely close to that of the LGM than that of the HO, even though the modern climate is closer to that of the $\mathrm{HO}$ rather than the LGM. This mismatching between the active sand dune distribution and the climate probably indicates that the climate was not the unique driver of the sand dune distribution, but other factors such as the human activity and clearing of the vegetation have significantly modified distribution of the active sand dunes in the northern China [47,64]. Our recently collected data of the Neolithic archaeological site distribution in the sand fields shows that human activity/ 
living sites have significantly increased since middle Holocene [65] (Table 2), demonstrating that the human activity has significantly been involved in land surface processes and vegetation clearing. This human impact is probably a major factor that remobilized the stable dunes in northern China during the late Holocene. More investigation is needed to clarify this question (When we revised this paper, we read a paper in Guangming Daily (March 25, 2013) that an ancient city of around 4000-5000 years ago was unearthed at Shimao site, Shenmu County, Shaanxi Province, at the transitional zone between the modern sand field and the loess deposition at southeastern margin of the Mu Us sand field. The archaeological report shows that the ancient city had an area of $4.0 \times 10^{6} \mathrm{~m}^{2}$ with the time of Huangdi (Yellow Emperor) era. The grand town proves that people had significantly influenced the surface process in this region since the middle Holocene).

There is an enigma that we did not find much well- preserved sand deposit of the LGM in these sand fields even we have analyzed numerous deposition records inside and out of the deserts and sand fields. Direct depositional evidences show that the sand fields of $\mathrm{Mu}$ Us and Horqin were existed since at least 1.0 Ma ago [23,66], demonstrating that the sand dunes were developed since at least that time. However, where are the dune sediments from the LGM? Here, we have three possible explanations: one is that the LGM sand sediments were still in the deserts and sand fields, but our OSL-based research methods did not detect it. Because the OSL dating technique indicates the time since the sediment was buried, we speculate that the wind was very strong and climate was very dry during the LGM, the sand dunes were mobile all the time, thus the sediments were continually re-exposed to light so no OSL signals/ages were acquired. Only when the wind velocity decreased and climate became relatively humid at the end of the LGM, was the sand sediment buried, so that the OSL "clock" started running. The second possibility is that the wind was strong and climate was very dry during the LGM, but there was relatively little new sediment brought into the sand fields because of drying of the rivers; at the same time, the strengthened winds transported existing sand sediments away, so there was little sediment preserved in the sand fields. The third possibility is that the extreme cold climate during the LGM in the sand fields, together with reduced evaporation, caused frequent sand surface stabilization by frost and snow; thus, there were not sand dunes formed. These explanations all need to be tested by more work, but

Table 2 Neolithic archaeological sites in the sand fields of northern China

\begin{tabular}{lcccc}
\hline \multicolumn{1}{c}{ Age } & Hulun Buir & Horqin & Hunshandake & Mu Us \\
\hline 9-4 ka & 42 & 579 & 30 & 467 \\
$4-2 \mathrm{ka}$ & 6 & 672 & 43 & 217 \\
Since 2 ka & 67 & 2932 & 171 & 934 \\
\hline
\end{tabular}

we prefer the first one at this stage.

\section{Conclusions}

Chinese deserts and sand fields have expanded $10 \%$ to $270 \%$ during the LGM, compared with their modern areas. The active sand dunes in the sand fields of northeast China were nearly completely stabilized, and the deserts in the northwest China have reduced $5 \%$ to $20 \%$ in area during the HO. The variations of Chinese deserts and sand fields were responded to paleoclimatic changes in the LGM and HO, but human activities have significantly modified the desert and sand field distribution in the late Holocene.

We thank Professors Dong Guangrong, Wang Sumin, Yang Gensheng, Zheng Du, Ding Zhongli, Liu Jiaqi, Fu Chongbin, An Zhisheng, Wang Ying, Chen Jun, Ji Junfeng and Gao Shu for their long-term guide and help; we also thank Yang Wenbin, Chu Jianmin, Chen Fahu, Sun Donghuai, Yan Ping, Zhou Liping, Zhang Jiafu, Lai Zhongping, Zhang Zhengcai, Yang Xiaoping, Sun Jimin, Wu Haibin, Qin Xiaoguang, Su Zhizhu for the valuable discussions. The two anonymous reviewers and editor provide constructive comments which improve quality of this paper. This work was supported by the Global Changes Program of Ministry of Science and Technology of China (2010CB950203), the Strategic Priority Research Program of the Chinese Academy of Sciences (XDA05120704), the National Natural Science Foundation of China (40930103 and 41021002), and China National Science and Technology Basic Work Program (2006FY110800 and 2012FY111700).

1 Wang $\mathrm{T}, \mathrm{Wu} \mathrm{W}, \mathrm{Xue} \mathrm{X}$, et al. Spatial-temporal changes of sandy desertified land during last 5 decades in Northern China (in Chinese). Acta Geogr Sin, 2003, 59: 203-214

2 Bush A B G, Rokosh D, Rutter N W, et al. Desert margins near the Chinese Loess Plateau during the mid-Holocene and at the Last Glacial Maximum: A model-data intercomparison. Glob Planet Change, 2002, 32: 361-374

3 Timm O, Timmermann A, DeCarlo S H. User-friendly data portal provides access to a transient paleoclimate simulation covering the last 21 kyr. PAGES News, 2009, 17: 4-5

4 Jin L Y, Chen F H, Morrill C, et al. Causes of early Holocene desertification in arid central Asia. Clim Dyn, 2012, 38: 1577-1591

5 Jiang D B, Tian Z P. East Asian monsoon change for the 21st century: Results of CMIP3 and CMIP5 models. Chin Sci Bull, 2013, 58: 1427-1435

$6 \mathrm{Wu} \mathrm{F}$ T, Fu C B. Change of precipitation intensity spectra at different spatial scales under warming conditions. Chin Sci Bull, 2013, 58: 1385-1394

7 Sarnthein M. Sand deserts during the glacial maximum and climatic optimum. Nature, 1978, 272: 43-46

8 Sun J M, Ding Z L, Liu T S. Desert distributions during the glacial maximum and climatic optimum: Example of China. Episodes, 1998, 21: $28-31$

9 Dong G R, Li B S, Gao S Y, et al. Discovery of Quaternary palaeoaeolian-sand in Ordos Plateau (in Chinese). Chin Sci Bull (Chin Ver), 1983, 28: 998-1001

10 Dong G R. Climate and Environmental Changes in Deserts of China (in Chinese). Beijing: China Ocean Press, 2002. 212-232

11 Jin $\mathrm{H}$ L, Dong G R, Su Z Z, et al. Reconstruction of the spatial patterns of desert/loess boundary belt in North China during the Holocene. Chin Sci Bull, 2001, 46: 969-974

12 Yang X P. Landscape evolution and precipitation changes in the Badain Jaran Desert during the last 30,000 years. Chin Sci Bull, 2000, 
45: $1042-1047$

13 Zhou W J, Dodson J, Head M J, et al. Environmental variability within the Chinese desert-loess transition zone over the last 20000 years. The Holocene, 2002, 12: 107-112

14 Yang X P, Rost K T, Lehmkuhl F, et al. The evolution of dry land in northern China and in the Republic of Mongolia since the Last Glacial Maximum. Quat Int, 2004, 118-119: 69-85

15 Chen H Z, Su Z Z, Yang P, et al. Preliminary reconstruction of the desert and sandy land distributions in China since the last interglacial period. Sci China Ser D-Earth Sci, 2004, 47(Supp 1): 89-100

16 Ding Z L, Sun J M, Rutter N W, et al. Changes in sand content of loess deposits along a north-south transect of the Chinese Loess Plateau and the implications for desert variations. Quat Res, 1999, 52: 56-62

17 Ding Z L, Derbyshire E, Yang S L, et al. Stepwise expansion of desert environment across northern China in the past 3.5 Ma and implications for monsoon evolution. Earth Planet Sci Lett, 2005, 237: 45-55

18 Lu H Y, Miao X D, Zhou Y L, et al. Late Quaternary aeolian activity in the Mu Us and Hunshandake dune fields (North China) and lagged response to insolation forcing. Geophys Res Lett, 2005, 32: L21716

19 Lu H Y, Wang X Y, Li L P. Aeolian sediment evidence that global cooling has driven late Cenozoic stepwise aridification in central Asia. Geol Soc Spec Publ, 2010, 342: 29-44

20 Wang X M, Li J J, Dong G R, et al. Responses of desertification to variations in wind activity over the past five decades in arid and semiarid China. Chin Sci Bull, 2008, 53: 424-433

21 Yang S L, Ding Z L. Advance-retreat history of the East-Asian summer monsoon rainfall belt over northern China during the last two glacial-interglacial cycles. Earth Planet Sci Lett, 2008, 274: 499-510

22 Fan Y X, Chen F H, Fan T L, et al. Sedimentary documents and Optically Stimulated Luminescence (OSL) dating for formation of the present landform of the northern Ulan Buh Desert, northern China. Sci China Earth Sci, 2010, 53: 1675-1682

23 Zeng L, Lu H Y, Yi S W, et al. Magnetostratigraphy of loess in northeastern China and paleoclimatic changes (in Chinese). Chin Sci Bull (Chin Ver), 2011, 56: 2267-2275

24 Wang N A, Li Z L, Cheng H Y, et al. High lake levels on Alashan Plateau during the Late Quaternary (in Chinese). Chin Sci Bull (Chin Ver), 2011, 56: 1367-1377

25 Yang L R, Ding Z L. Expansion and contraction of Hulun Buir Dunefield in north-eastern China in the last late glacial and Holocene as revealed by OSL dating. Environ Earth Sci, 2013, 68: 1305-1312

26 Liu B, Jin H L, Sun Z. Progress of studies of climate and environment changes in Gonghe basin, northeastern Tibetan Plateau, since the Last Glacial Maximum period (in Chinese). J Glaciol Geocryol, 2012, 34: 403-410

27 Li J J. The patterns of environmental changes since Late Pleistocene in northwestern China (in Chinese). Quat Sci, 1990, 10: 197-204

28 Yu G, Chen X, Liu J, et al. Preliminary study on LGM climate simulation and the diagnosis for East Asia (in Chinese). Chin Sci Bull (Chin Ver), 2001, 46: 364-368

$29 \mathrm{Wu} \mathrm{H} \mathrm{B}$, Guo Z T. Evolution and drought events in arid region of northern China since the Last Glacial Maximum (in Chinese). Quat Sci, 2000, 20: 548-558

30 Vandenberghe J, Renssen H, Huissteden K V, et al. Penetration of Atlantic westerly winds into Central and East Asia. Quat Sci Rev, 2006, 25: 2380-2389

31 Chen F H, Yu Z C, Yang M L, et al. Holocene moisture evolution in arid central Asia and its out-of-phase relationship with Asian monsoon history. Quat Sci Rev, 2008, 27: 351-364

32 Zhu F Y, Lu H Y, Zhang W C, et al. Mapping deserts and sandy fields in Northern China and the surface process dynamics based on 3S techniques (in Chinese). Quat Sci, 2013, 33: 197-205

33 Murray A S, Wintle A G. Luminescence dating of quartz using an improved single-aliquot regenerative-dose protocol. Radiat Meas, 2000, 32: 57-73

34 Lu H Y, Mason J A, Stevens T, et al. Response of surface processes to climatic change in the dunefields and Loess Plateau of North China during the late Quaternary. Earth Surf Proc Land, 2011, 36: 1590-
1603

35 Lu H Y, Zhou Y L, Mason J, et al. Late Quaternary climatic changes in Northern China-New evidences from sand dune and loess records based on optically stimulated luminescence dating (in Chinese). Quat Sci, 2006, 26: 888-894

36 Zhou Y L, Lu H Y, Mason J, et al. Optically stimulated luminescence dating of aeolian sand in the Hunshandake dune field and Holocene climate change. Sci China Ser D-Earth Sci, 2008, 51: 837-847

37 Zhou Y L, Lu H Y, Zhang J F, et al. Luminescence dating of sand-loess sequences and response of $\mathrm{Mu}$ Us and Hunshandake sand fields (north China) to climatic changes. J Quat Sci, 2009, 24: 336-344

38 Mason J A, Lu H Y, Zhou Y L, et al. Dune mobility and aridity at the desert margin of northern China at a time of peak monsoon strength. Geology, 2009, 37: 947-950

39 Stevens T, Lu H Y, Thomas D S G, et al. Optical dating of abrupt shifts in the late Pleistocene East Asian monsoon. Geology, 2008, 36: 415-418

40 Yi S W, Lu H Y, Zeng L, et al. Paleoclimate changes and reconstruction of the border of Horqin dunefield (Northeastern China) since the Last Glacial Maximum (in Chinese). Quat Sci, 2013, 33: 206-217

$41 \mathrm{Xu} \mathrm{Z} \mathrm{W,} \mathrm{Lu} \mathrm{H} \mathrm{Y,} \mathrm{Yi} \mathrm{S} \mathrm{W,} \mathrm{et} \mathrm{al.} \mathrm{Spatial} \mathrm{variations} \mathrm{of} \mathrm{the} \mathrm{Mu} \mathrm{Us} \mathrm{dune}$ field (north central China) during Last Glacial Maximum and Holocene Optimum (in Chinese). Quat Sci, 33: 218-227

42 Zhou Y L, Lu H Y, Zhang X Y, et al. Changes of the border of Hunshandake (Otindag) sand field (Northern China) during the Last Glacial Maximum and Holocene Optimum (in Chinese). Quat Sci, 2013, 33: 228-242

43 Zeng L, Lu H Y, Yi S W, et al. Environmental changes of Hulun Buir dunefield in northeastern China during the Last Glacial Maximum and Holocene Optimum (in Chinese). Quat Sci, 2013, 33: 243-252

44 Zhou Y L, Lu H Y, Zhang J F, et al. Active and inactive phases of sand-dune in $\mathrm{Mu}$ Us and Otindag sand lands during Late Quaternary suggested by OSL dating (in Chinese). J Desert Res, 2005, 25: 342-350

45 Gao S Y, Chen W N, Jin H L, et al. A preliminary study of paleoclimate changes at margins of Chinese eastern deserts in the Holocene (in Chinese). Sci China Ser B, 1993, 23: 202-208

46 Dong G R, Wang G Y, Li X Z, et al. Palaeomonsoon vicissitudes in eastern desert region of China since last interglacial period. Sci China Ser D-Earth Sci, 1998, 41: 215-224

47 Sun J M. Origin of eolian sand mobilization during the past 2300 years in the Mu Us Desert, China. Quat Res, 2000, 53: 78-88

48 Li S H, Sun J M, Zhao H. Optical dating of dune sands in the northeastern deserts of China. Palaeogeog Palaeoclimatol Palaeoecol, 2002, 181: 419-429

49 Li S H, Sun J M. Optical dating of Holocene dune sands from the Hulun Buir desert, Northeastern China. The Holocene, 2006, 13: $457-462$

50 Li S H, Fan A C. OSL chronology of sand deposits and climate change of last $18 \mathrm{ka}$ in Gurbantunggut Desert, northwest China. J Quat Sci, 2011, 26: 813-818

51 Li B, Li S H, Sun J M. Isochron dating of sand-loess-soil deposits from the Mu Us Desert margin, central China. Quat Geochron, 2011, 6: 556-563

52 Zhao H, Lu Y C, Yin J H. Optical dating of Holocene sand dune activities in the Horqin sand-fields in Inner Mongolia, China, using the SAR protocol. Quat Geochronol, 2007, 2: 29-33

53 He Z, Zhou J, Lai Z P, et al. Quartz OSL dating of sand dunes of Late Pleistocene in the Mu Us Desert in northern China. Quat Geochronol, 2010, 5: 102-106

54 Ma J, Yue L P, Yang L R, et al. OSL dating of Holocene sequence and palaeoclimate change record in southeastern margin of Mu Us desert, north China (in Chinese). Quat Sci, 2011, 31: 120-129

55 Yang L H, Zhou J, Lai Z P, et al. Lateglacial and Holocene dune evolution in the Horqin dunefield of northeastern China based on luminescence dating. Palaeogeog Palaeoclimatol Palaeoecol, 2010, 296: 44-51

56 Yang L H, Wang T, Zhou J, et al. OSL chronology and possible 
forcing mechanisms of dune evolution in the Horqin dunefield in northern China since the Last Glacial Maximum. Quat Res, 2012, 78: 185-196

57 Yu L P, Lai Z P. OSL chronology and palaeoclimatic implications of aeolian sediments in Qaidam Basin of northeastern Qinghai-Tibetan Plateau. Palaeogeog Palaeoclimatol Palaeoecol, 2012, 337-338: 120 129

58 Duller G A T, Wintle A G. A review of the thermally transferred optically stimulated luminescence signal from quartz for dating sediments. Quat Geochronol, 2012, 7: 6-20

59 Dong G R, Jin H L, Chen H Z. Desert-loess boundary belt shift and climatic change since the last interglacial period (in Chinese). Quat Sci, 1997, 2: 158-167

60 Guo Z T, Petit-Maire N, Kröpelin S. Holocene non-orbital climatic events in present-day arid areas of northern Africa and China. Glob Planet Change, 2000, 26: 97-103

61 Dong G R, Li B S, Wen X L. Features of aeolian landform in China and the evolution. In: Yang J C, ed. Features of Landform and the Evolution in China (in Chinese). Beijing: China Ocean Press, 1993. 149-172

62 Yung Y L, Lee T, Wang C H, et al. Dust: A diagnostic of the hydrologic cycle during the Last Glacial Maximum. Science, 1996, 271 : 962-963

63 Clark P U, Dyke A S, Shakun J D, et al. The Last Glacial Maximum. Science, 2009, 325: 710-714

64 Lu H Y, Zhou Y L, Liu W G, et al. Organic stable carbon isotopic composition reveals late Quaternary vegetation changes in the dune fields of northern China. Quat Res, 2012, 77: 433-444

65 Zhuo H X, Lu H Y, Jia X, et al. A preliminary study on human activities in sand fields of northern China and its relationship with the climatic variations in Holocene (in Chinese). Quat Sci, 2013, 33: $303-313$

66 Xiong S F, Ding Z L, Liu T S. Climatic implications of loess deposits from the Beijing region. J Quat Sci, 2001, 16: 575-582

Open Access This article is distributed under the terms of the Creative Commons Attribution License which permits any use, distribution, and reproduction in any medium, provided the original author(s) and source are credited. 